\title{
PENGARUH JOB-ENGAGEMENT TERHADAP PERILAKU WITHDRAWAL MELALUI KOMITMEN ORGANISASI
}

\author{
Alkusani $^{1^{*}}$ \\ Sukaris $^{1 *}$ \\ ${ }^{1}$ Program Studi Manajemen \\ Fakultas Ekonomi dan Bisnis \\ Universitas Muhammadiyah Gresik \\ alkusani@umg.ac.id
}

\begin{abstract}
Human resources (HR) as one of the keys for the company in achieving its goals and success. Achieving company goals if HR shows good reliability, therefore companies need to make HR play a key role in an organization so that there is involvement, love or employee engagement that impacts on the sustainability of an organization, which can build organizational commitment and also determine how employees will behave. In this study offers a new theoretical framework of management as a shaping factor for the importance of organizational commitment and also the behavior of withdrawal of employees, the sample is carried out on employees with a contractual status of 54 in a higher education institution. The analysis tool uses path analysis with warpPLS. The results show that job engagement negatively influences employee organizational commitment, job engagement has a negative influence on withdrawal behavior, organizational commitment has a negative influence on withdrawal behavior while organizational commitment cannot be a mediating variable between job engagement and employee withdrawal behavior .
\end{abstract}

Keywords : engagement, organizational commitment, withdrawal

\section{PENDAHULUAN}

Perkembangan dewasa ini dapat dilihat dengan terjadinya akselerasi perubahan lingkungan yang dinamis dan multikompetitif, diantaranya dengan terjadi kompleksitas permasalahan kehidupan disatu sisi dan disisi yang lain adanya perubahan yang tak terelakkan dalam organisasi bisnis yang menyangkut semua elemen didalamnya dan elemen-elemen lain diluar organisasi tersebut, sehingga memunculkan kompleksnya permasalahan yang dihadapi oleh organisasi terkait dengan permasalahan persaingan dalam lingkungan bisnis.

Fenomena persaingan bisnis yang terjadi akhir-akhir ini, tentu selain memunculkan tantangan baru juga memberikan sebuah peluang bagi organisasi untuk membuat konsep manajemen yang efektif-efisien melalui manajemen sumberdaya-manusia (SDM). SDM seharusnya lebih proaktif-responsif dengan permasalahan tersebut tidak sekedar bekerja atau penyelesaian tugas saja, semua aktivitas dan tugas yang dilakukan harus dapat memiliki nilai tambah bagi pencapai tujuan organisasi, mengantisipasi berbagai perkembangan sebagai bagian perubahan paradigma baru bahwa manajemen SDM bagian penting dalam terlibat membuat pencapaian kesuksesan perusahaan sebagai tujuan akhir keberadaan perusahaan itu sendiri.

SDM sebagai asset berperan kunci dalam perusahaan untuk mencapai tujuan dan kesuksesan. Pencapaian tujuan ini akan terlaksana jika SDM menunjukkan performa kerja yang unggul, untuk itu perusahaan perlu memperhatikan SDM yang ada dalam suatu organisasi agar tercipta keterlibatan atau employee-engagement yang berdampak pada keberlangsungan suatu organisasi, bagaimanapun sebuah perusahaan tidak akan 
dapat berjalan tanpa didukung oleh SDM yang handal dan sesuai dengan visi-misi perusahaan. Perusahaan perlu memperhatikan investasi SDM dalam organisasinya dan menciptakan employeeengagement maka diperlukan pengelolaan dan pengorganisasian secara terarah dan perusahaan tanggap terhadap kebutuhan karyawan karena kehilangan atau sering terjadinya turnover karyawan bukanlah sebuah pilihan.

Engagement telah memiliki peran penting dalam organisasi dan bagaimana telah mempengaruhi orang-orang dalam organisasi di dunia Berdasarkan survey terkait engagement memiliki kerkaitan erat dengan: 1) Pelayanan pelanggan, 2) Tanggung jawab terhadap keselamatan kerja, 3) Biaya penerimaan dan pelatuhannya, 4) Kesehatan karyawan, 5) Produktivitas, atau prestasi

Secara khusus saat ini, semakin pentingnya organizational-engagement bagi organisasi karena selama ini organisasi fokus pada loyalitas karyawan (employee loyalty) telah dijadikan strategi agar dapat meminimalisir resiko turnover di perusahaan bahkan juga perilaku withdrawal, akan tetapi loyalitas karyawan (employee loyalty) masih belum cukup memenuhi kebutuhan perusahaan saat ini, mereka memang terpuaskan sehingga enggan untuk pindah ke perusahaan lain/perusahaan kompetitor sejenis, namun belum ada inovasi untuk bagaimana caranya selain karyawan itu loyal, atau berkomitmen terhadap organisasi mereka juga menjadi sosok orang-orang yang dapat berkontribusi secara proaktif kepada perusahaan.

Secara konseptual bahwa employeeengagement berhubungan dengan perilaku organisasi namun tetap berbeda termasuk di dalamnya adalah komitmen organisasi. Employee-engagement dalam literature akademis telah didefinisikan sebagai konstruk yang terdiri dari elemen kognisi, emosi dan konasi yang berkorelasi dengan tujuan perusahaan. Hal ini sesuai dengan yang diungkapkan oleh Martha bahwa employee enggament berbeda dengan komitmen organisasi. Komitmen organisasi lebih kepada sikap dan kedekatan dengan organisasi. Sedangkan enggagemnt menitikberatkan pada peran yang dilakukan diperusahaan.

Engagement sebagaimana dinyatakan Handoko (2012) menyatakan keterlibatan karyawan (employee engagement) engagement) menyatakan seberapa kuat karyawan bergairah dan senang dalam melakukan aktivitas pekerjaan. Karyawan yang engage adalah yang benar-benar memiliki antusias dan kecintaan terhadap apa yang dikerjakan dan apa yang dilakukan untuk lembaga dimana dia berada. Keterlibatan/kecintaan adalah mau dan mampu untuk memberikan kontribusi terhadap kesuksesan organisasi (lembagaperusahaan), Luthans (2006) mengatakan komitmen sebagai sikap, komitmen organisasi paling sering didefinisikan sebagai berikut: "1. keinginan yang kuat dan tetap sebagai bagian dari organisasi; 2. Keinginan yang besar sesuai apa yang diharapkan oleh organisasi 3. Menerima dengan rela dan melakukan nilai-nilai, budaya dan tujuan organisasi. Allen dan Meyer (Luthans, 2006) komitmen organisasi terdiri dari tiga elemen penting yaitu: a) komitmen-afektif sebagai ikatan emosional karyawan, identifikasi, dan keterlibatan dalam organisasi; b) komitmenkontinum sebagai komitmen berdasarkan untung rugi dengan keluar masuk karywan yang dihubungkan dengan senioritas atas promosi atau manfaat; c) komitmennormative adanya peran yang tidak bisa ditinggalkan sehingga tetap berada dalam organisasi karena memang harus demikian.

Henle et al.,(2010) menjelaskan sikap sebagai keyakinan afektif (apa yang dirasakan) dan evaluatif (apa yang telah dilakukan). Sikap sebagai fungsi dari keyakinan berperilaku, yang bersumber dari perilaku dan evaluasinya. Apabila perilaku memiliki kecenderungan sesuai yang diinginkan maka penilaiannya juga akan lebih baik.. maka sikap seseorang yang melihat bahwa perilaku withdrawal 
memberikan kebermanfaatan bagi dirinya sendiri, maka dimungkin seseorang individu tersebut telah berperilaku withdrawal

Penerapan engagement di Indonesia? sejak dikenalkan oleh Gallup tahun 2004, penerapan ini bisa kita lihat semakin banyaknya assessment terkait dengan engagement missal di dunia perbankan terdapat survey EEI (employee engagement Indexs), dalam Sebuah studi global workforce pada tahun 2012 Hasil survey menunjukkan bahwa: 1) 2/3 Karyawan Indonesia tidak memiliki engagement yang tinggi terhadap perusahaan; 2) $27 \%$ karyawan merencanakan pindah; 3) 42\% dari 1.005 karyawan berniat hengkang dari perusahaan; dan 4) $36 \%$ karyawan diperusahaan memiliki engagement. Dalam survey ini juga dinilai engagement indeks Indonesia mengalami peningkatan $27 \%$ skor engagement Indonesia merangkak naik dari $64 \%$ menjadi $71 \%$. Dimana skor tertinggi dari 11 negara di Asia Pasifik. (www.portalHR.com)

Berdasarkan kondisi demikian maka disadari bahwa Human Ressources sebagai asset penting perusahaan, khususnya mengenai engagement sebagai pembentuk komitmen organisasi dan juga perilaku withdrawal. Penelitian ini mereview secara kritis teori enggagement yang dihubungkan dengan perilaku penghindaran pekerjaan (withdrawal) melalui komitmen organisasi.

\section{TINJAUAN PUSTAKA \\ Engagement}

Keterlibatan adalah perasaan dan energi yang difokuskan pada tujuan, individu memiliki inisiatif, kemampuan beradaptasi, usahausaha, dan kegigihan yang diarahkan pada tujuan organisasi. (Macey, 2009)

Handoko (2012) employee-engagement menguraikan kegairahan dan perasaan bahagia dalam aktivitas pekerjaan. Karyawan secara sukarela terikat, larut dalam pekerjaan, mengerahkan semua sumberdaya pribadi, kemampuan, kemauan dan energi untuk mencapai tujuan-organisasi
Mone \& London, (2018) bahwa resources yang berfokus pada organisasi, organisasi iklim keterlibatan, mempengaruh engagemen karyawan. Mone juga menjelaskan bahwa pengukuran dari engagemen karyawan adalah di tempat kerja, merasa meledak dengan energi, di pekerjaan karyawan merasa kuat dan kuat, karyawab sangat antusias dengan pekerjaan, pekerjaan menginspirasi karyawab, Ketika karyawan bangun di pagi hari, merasa ingin bekerja, karyawan merasa senang ketika bekerja dengan intens, karyawan bangga dengan pekerjaan yang dilakukan, karyawan larut dalam pekerjaan dan terbawa ketika saya bekerja

Macey, (2009) bahwa employeeengagement akan terlihat sebagai berikut

1) Berpikir secara proaktif, bahwa karyawan melakukan antisipasi peluang-peluang yang tersedia untuk melakukan upaya nyata yang disesuaikan dengan tujuan organisasi.

2) Meluaskan pikiran, karyawan menggunakan cara-cara baru tidak terjebak dengan cara-cara lama, namun menggunakan pendekatan baru dalam upaya untuk mencapai tujuan organisasi sepanjang apa yang dilakukan masih dalam bagian pekerjaannya.

3) Aktif dalam meningkatkan keahliannya, pengembangan diri menjadi bagian penting dalam upaya berkontribusi lebih terhadap setiap usaha pencapaian tujuan organisasi yang efektif . kata kuncinya adalah kemampuan member buka menerima.

4) Persistensi, daya juang yang tinggi dalam setiap hambatan yang ada tanpa harus mudah menyerah.

Penelitian terdahulu terkait dengan engagement dan komitmen organisasi; Sunarto (2016) bahwa employee-engagement memiliki pengaruh yang signifikan terhadap Komitmen organisasional Karyawan"; Rich \& Crawford (2010) menyatakan terdapat pengaruh job-engagement terhadap organizational-citizenship-behavior; Andrew \& Sofian (2012) Individual Factors of 
Employee Engagement and Work Outcomes yaitu ada pengaruh antara job-engagement terhadap komitmen organisasi.

\section{Withdrawal Attitudes}

Henle et al., (2010) menjelaskan sikap sebagai keyakinan afektif (apa yang dirasakan) dan evaluatif (apa yang telah dilakukan). Sikap sebagai fungsi dari keyakinan berperilaku, yang bersumber dari perilaku dan evaluasinya. Apabila perilaku memiliki kecenderungan sesuai yang diinginkan maka penilaiannya juga akan lebih baik.. maka sikap seseorang yang melihat bahwa perilaku withdrawal memberikan kebermanfaatan bagi dirinya sendiri. Henle et al., juga menggunakan istilah time-theft sebagai aktivitas yang dilakukan yang tidak berhubungan dengan pekerjaan, contoh terlambat datang ke tempat pekerjaan, pulang lebih awal dari tempat kerja, lebih lama dalam waktu istirahatnya (tidur-tiduran). Kegiatan ini ditengarai tidak sesuai dengan apa yang menjadi perjanjian kerja maupun prosedur pekerjaan padahal disisi lain karyawan telah menerima hakhaknya namun tidak ada hasil pekerjaan yang dilakukan

Kolowsky et al., (1997), withdrawalattitudes merujuk pada kumpulan perilaku yang digunakan oleh kayang dibebabnkan kepadanya. Perilaku-perilaku ini bisa tampak seperti; terlambat datang, lebih cepat pulang, banyak catatan ketidakhadiran, selalu berkeliling ketempat lain, bermalas-malasan, lalai dalam tugasnya, mengulur-ngulur waktu istirahat, bersosialisasi yang berlebihan pada rekan kerja selama pekerjaan berlangsung.

Kolowsky, (2000). withdrawalattitudes mengacu pada serangkaian sikap dan perilaku yang digunakan oleh karyawan ketika mereka tetap bekerja, tetapi karena alasan tertentu memutuskan untuk menjadi kurang partisipatif (Kaplan et al., 2009). withdrawal-attitude, didefinisikan sebagai serangkaian tindakan yang dilakukan karyawan untuk menghindari situasi kerja perilaku yang pada akhirnya dapat berujung pada pengunduran diri organisasi (Hulin, 1991;Mirsepasi, 2012)

Penelitian penelitian sebelumnya menunjukkan bahwa ada hubungan antara job-engagement dengan niat untuk keluar dari pekerjaan, Saragih \& Margaretha (2013); Yulianti (2016); Sadana \& Vany (2014)

\section{Komitmen Organisasi}

Luthans, 2006) komitmen organisasi terdiri dari tiga elemen penting yaitu: a) komitmen-afektif sebagai ikatan emosional karyawan, identifikasi, dan keterlibatan dalam organisasi; b) komitmen-kontinum sebagai komitmen berdasarkan untung rugi dengan keluar masuk karywan yang dihubungkan dengan senioritas atas promosi atau manfaat; c) komitmen-normative adanya peran yang tidak bisa ditinggalkan sehingga tetap berada dalam organisasi karena memang harus demikian.

Allen dan Meyer (Luthans, 2006) komitmen organisasi terdiri dari tiga elemen penting yaitu: a) komitmen-afektif sebagai ikatan emosional karyawan, identifikasi, dan keterlibatan dalam organisasi; b) komitmenkontinum sebagai komitmen berdasarkan untung rugi dengan keluar masuk karywan yang dihubungkan dengan senioritas atas promosi atau manfaat; c) komitmennormative adanya peran yang tidak bisa ditinggalkan sehingga tetap berada dalam organisasi karena memang harus demikian.

Banyak studi terbaru terhadap komitmen organisasi mengakui bahwa komitmen ini adalah multidimensi. Perkembangan multidimensi dapat dikaitkan dengan karya Allen \& Meyer (1990), yang mengklasifikasikan organisasi Komitmen dalam tiga kategori ikatan emosional (afektif), apa yang dirasakan (Kelanjutan), dan kewajiban (normatif) dan kategori ini telah diadopsi sebagai dasar untuk penelitian ini, mengingat bahwa mereka telah paling banyak digunakan dan langkah-langkah yang diterima dari komitmen organisasi dalam literatur (Klein et al., 2009). "komitmenorganisasi didefinisikan sebagai pengaruh identifikasi karyawan dan keterlibatan 
dengan organisasi tertentu "(Newman et al, 2011; Steers, 1977). Model yang paling umum digunakan adalah model tiga komponen yang dikembangkan oleh Meyer et al.,(1993). Selain itu, Allen \& Meyer (1990) telah menganalisis teori komitmen organisasi secara mendalam, dan telah secara luas diuji baik afektif dan komitmen normatif. Namun, Wagner (2007) menyatakan bahwa tidak ada kekurangan penelitian yang telah menyelidiki anteseden dari komitmen karyawan.

Hasil mengungkapkan bahwa afektif dan normative komitmen berhubungan negatif dengan niat perputaran karyawan, yang meniru temuan penelitian sebelumnya pada konteks organisasi Cina (Chen \& Francesco,2000; Cheng \& Stockdale, 2003; Newman et al., 2011). Namun, itu cocok baik teori dari keinginan dengan harapan (Porter \& Steers, 1973) dan teori kontrak psikologis. Secara khusus, karyawan yang keinginan dan harapan tercapai dan yang memandang puas dengan kontrak psikologis, mereka mengembangkan tambahanp sikologis lebih besar terhadap organisasi mereka, sehingga lebih kecil kemungkinannya bahwa mereka akan meninggalkan organisasi. Dari perspektif praktis, pengusaha bisa menginspirasi karyawan untuk menganggap organisasi sebagai keluarga (Chen \& Francesco, 2000), yang mereka mungkin lebih termotivasi untuk mengerahkan usaha mereka. Hal ini kemudian dapat bermanifestasi sebagai lebih menonjol niat untuk tetap dalam organisasi

\section{Hipotesis Penelitian}

Berdasarkan teori yang telah disajikan, maka hipotesis yang diajukan:

H1: Job-engagement berpengaruh terhadap komitment organisasi

$\mathrm{H} 2$ : Jo -engagement berpengaruh terhadap perilaku withdrawal

H3: Komitment-organisasional berpengaruh terhadap perilaku witdrawal

H4: Job-engagement berpengaruh terhadap perilaku withdrawal melalui komitmen organisasi

\section{METODOLOGI PENELITIAN}

Desain penelitian yang digunakan pada penelitian ini adalah desain kuantitatif. desain kuantitatif digunakan karena dengan pendekatan ini proses penelitian dilakukan secara terstruktur dan menggunakan sampel penelitian. Teknik pengambilan sampel dilakukan secara jenuh sehingga dalam penelitian ini karyawan sejumlah 54 orang yang berstatys tentative atau outsourcing. Lokasi penelitian ini dilakukan di Universitas Muhammadiyah Gresik pada pegawai khususnya pada pegawai staf adminstrasi yang berstatus tidak tetap

Variabel yang diamati atau diukur, Untuk memudahkan pemahaman variabel penelitian ini berikut disampaikan rujukan definisi operasional variabel;

1. Job-engagement merujuk pada penelitian Saks, A.M. (2006)

2. Komitmen organisasi mengacu pada pendapat Luthans (2006

3. Perilaku-withdrawal adalah mendasarkan pendapat Colquitt, et al., ( 2012); Arviana, (2013).

Sumber data penelitian merujuk pada sumber data primer yaitu data yang diperoleh melalui hasil pengumpulan kuesioner kepada pengguna karyawan atau sampel yang telah dipilih dan sesuai dengan kuesioner yang dibuat, dengan menggunakan skala likert, maka data yang terkumpul adalah data interval (Emory dan Cooper, 1996). Sedangkan data sekunder yang digunakan hanya untuk data pendahuluan dan bersifat sebagai data penunjang yang didapat dari jurnal-jurnal, literatur-literatur, dan referensi lainnya.

Teknik pengumpulan data primer dalam penelitian sebagai cara bagaimana data dikumpulkan yaitu data yang dikumpulkan langsung dari responden dalam hal ini mahasiswa yang aktif. untuk menguji sahih dan keterpercayaan instrumen kuisiner dilakukan validity dan reliability test

Dalam menjawab tujuan penelitian, menguji hubungan antar variabel dan menilai model yang disusun, teknik analisis yang digunakan adalah teknis analisis jalur dibantu 
dengan software WarpPLS, Model persamaan penelitian sebagaimana disajikan dalam gambar 1 .

Pengujian hipotesis yang telah disajikan pada bab dua maka digunakan $\mathrm{P}$ value, dengan kreteria pengambilan keputusan hipotesis penelitian di terima jika $\mathrm{P}$ value lebih kecil dari 0.05 .

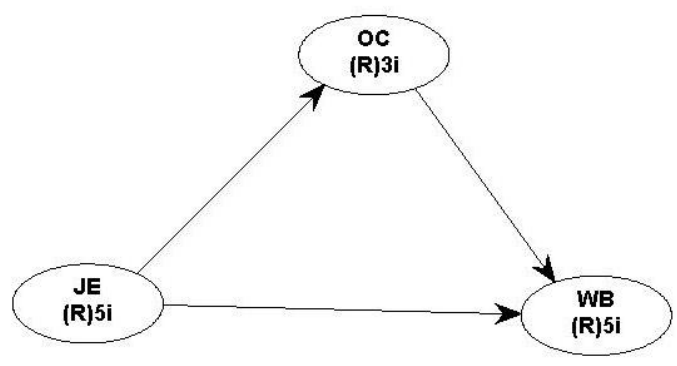

Gambar 1: Model Persamaan

Keterangan: JE: job-engagement OC: Komitmen organisasi dan WB: Prilaku witdrawal

\section{HASIL DAN PEMBAHASAN}

\section{Hasil}

Pada tahap menganalisas hasil pengolahan data penelitian ini digunakan metode inferensial untuk menguji tujuan penelitian. Dengan maksud untuk mengetahui pengaruh positif atau negatif arah variabel bebasa terhadap variabel terikat dengan analisis jalur dibantu software WarpPLS. Sebelum dilakukan pengujian regresi dilakukan pengujian validity dan reliability test

Hasil validity dan reliability test tahap pertama dketahui bahwa terdapat indikator yang nilainya dibawah 0.5 , sehingga dikeluarkan dari pengukur variabel yaitu indikator pada X1.5, Y1.1 dan Y1.5 sehingga dilakukan pengukuran ulang dengan validitas dengan hasil semua indikator nilainya sudah memenuhi diatas 0.5. sedangkan nilai reliabilitas dihasilkan dengan nilai composite reliability coeficient dengan nilai untuk variabel job-engagement 0.876, untuk organizational commitment sebesar 0.744 dan nilai untuk withdrawal behavior sebesar
0.743 sehinga nilai tersebut sudah diatas nilai 0.7 sebagai syarat diterimanya pengujian reliabilitas.

Pengujjian kecocokan model diperoleh hasil Average path coefficient $($ APC $)=0.262$, $\mathrm{P}=0.010$, Average R-squared (ARS) $=0.118$, $\mathrm{P}=0.092$, Average adjusted R-squared (AARS) $=0.093, \mathrm{P}=0.120$, Average block VIF $(\mathrm{AVIF})=1.036$, diterima jika $<=5$, idealnya $<=3.3, \quad$ Average full collinearity VIF $(\mathrm{AFVIF})=1.052$, diterima jika $<=5$, idealnya $<=\quad$ 3.3.berdasarkan hasil tersebut disimpulkan bahwa model adalah fit.

Dalam menjawab tujuan penelitian dan hipotesis maka dilakukan analisis data dengan hasil sebagaimana model yang disajikan sebagai berikut:

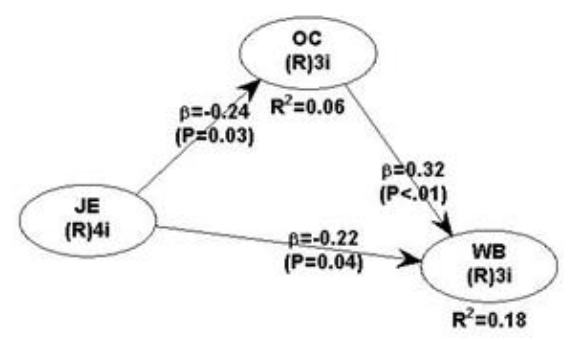

Gambar 2: Hasil Uji Model

Hasil Tersebut menunjukkan bahwa: 1) Diketahui pada jalur JE $\rightarrow$ OC, hasl koefisien jalur sebesar -0.24 dengan $p$ value sebesar 0.003 sehingga hasil mendukung hipotesis yang diajukan yaitu terdapat pengaruh jobengagement terhadap komitmen organiasi; 2) Diketahui pada jalur JE $\rightarrow \mathrm{WB}$, bahwa koefisien jalur sebesar -0.22.dengan $\mathrm{p}$ value sebesar 0.04, sehingga hasil tersebut mendukung job- engagement berpengaruh terhadap perilaku withdrawal; 3) Diketahui pada jalur OC $\rightarrow \mathrm{WB}$, bahwa koefisien jalur sebesar 0.34 , dengan $\mathrm{p}$ value sebesar 0.01 sehingga hasil tersebut mendukung hipotesis yang diajukan komitmen organiasi berpengaruh terhadap perilaku withdrawal; dan Pengaruh antara job-engagement terhadap perilaku withdrawal yang dimediasi oleh komitmen organisasi dengan $(\mathrm{JE} \rightarrow \mathrm{OC} \rightarrow \mathrm{WB})$ hasil estimasi sebesar 0.077 dengan $\mathrm{P}$ value sebesar 0.205, 
sehingga hasil ini tidak mendukung hipotesis yang diajukan.

\section{PEMBAHASAN}

Dengan hasil yang diperoleh maka pembahasan untuk masing-masing hasil yang didasarkan pada pengujian hipotesis yang telah dilakukan.

Pengaruh job-engagement terhadap komitmen organiasasi diketahui nilai estimasi koefisien jalur sebesar -0.24 dengan $\mathrm{p}$ value sebesar 0.003 , artinya bahwa ada hubungan negatif antara job-engagemen terhadap komitmen-organisasi, hasil ini menunjukkan bahwa nilai negative memberikan tafsiran semakin tinggi keterlibatan karyawan (job-engagement) terhadap pekerjaan maka akan semakin rendah komitmen organisasionalnya. Penelitian ini tentu paradox dengan beberapa penelitian terdahulu yang mana semakin tinggi keterlibatan dalam pekerjaan semakin tinggi komitmen organisasionalnya Sunarto (2016) bahwa employee-engagement berpengaruh signifikan terhadap komitmen organisasional karyawan; Rich \& Crawford (2010) ada pengaruh job-engagement terhadap organizational-citizenship-behavior; Andrew \& Sofian (2012) ada pengaruh positif antara job-engagement dengan komitmen organisasi.

Pengaruh job-engagement berpengaruh terhadap perilaku withdrawal diketahui bahwa hasil estimasi koefisien jalur sebesar 0.22.dengan $\mathrm{p}$ value sebesar 0.04 , artinya bahwa ada hubungan negatif antara jobengagement terhadap perilaku witdrwal, hasil ini menunjukkan bahwa semakin tinggi keterlibatan karyawan atas pekerjaannya maka akan semakin rendah perilaku withdrawalnya, hasil ini mendukung beberapa penelitian terdahulu diantaranya adalah Saragih \& Margaretha (2013); Yulianti (2016); Sadana \& Vany (2014) dan Chairiza et al., (2018).

\section{Pengaruh}

komitmen-organisasi terhadap perilaku-withdrawal diketahui bahwa hasil estimasi koefisien jalur sebesar 0.34 , dengan $\mathrm{p}$ value sebesar 0.01 sehingga hasil memberikan tanda bahwa komitmen organisasi berpengaruh positif terhadap perilaku withdrawal, hasil ini tidak mendukung penelitian-penelitian terdahulu job-engagement berpengaruh negatif terhadap perilaku withdrawal (Chen \& Francesco,2000; Cheng \& Stockdale, 2003; Newman et al., 2011).

Pengaruh antara job-engagement terhadap perilaku withdrawal yang dimediasi oleh komitmen organisasi dengan (JE $\square$ OC $\square$ WB) hasil estimasi sebesar -0.077 dengan $P$ value sebesar 0.205 , sehingga hasil ini tidak mendukung hipotesis yang diajukan, hasil ini juga tidak mampu menjadi variabel mediasi antara job-engagement terhadap perilaku withdrawal karyawan.

\section{SIMPULAN}

Bahwa "job-engagement berpengaruh negatif terhadap komitmen organiasional karyawan, job-engagement berpengaruh negatif terhadap perilaku withdrawal karyawan, komitmen organisasional berpengaruh negatif terhadap perilaku withdrawal karyawan sedangkan komitmen organisasi tidak mampu menjadi variabel mediasi antara job-engagement terhadap perilaku withdrawal karyawan".

Dampak pada implikasi managerial, bahwa dalam hasil penelitian ini penting membangun keterikatan atau keterlibatan karyawan dalam pekerjaan, ini menandai bahwa semakin tinggi karyawan terbangun rasa cinta, merasa terlibat dalam pekerjaan maka karyawan akan semakin kecil terjadinya perilaku withdrawal (penghindaran pekerjaan) walaupun dalam konteks karyawan yang masih bersifat tentatif (kontrak) .

Dampak Implikasi teoritikal, bahwa perlu pengujian dan análisis kembali hubungan antara job-engagement dengan komitmen organisasi dan komitmen organisasi terhadap perilaku withdrawal, karena hasil ini memiliki nilai negatif namun demikian penelitian ini mengambil sampel tenaga kontrak sehingga perlu dipertimbangkan pengaruh tersebut, 
demikian juga dapat dilakukan penelitian yang melakukan perbandingan antara kelompok karyawan yang tetap dan juga karyawan yang kontrak.

\section{DAFTAR PUSTAKA}

Allen, N.J. and Meyer, J.P. (1990), "The measurement and antecedents of affective, continuance and normative commitment to the organization", Journal of Occupational Psychology, Vol. 63 No. 1, pp. 1-18.

Albrecht, S., Breidahl, E., \& Marty, A. (2018). Organizational resources, organizational engagement climate, and employee engagement. Career Development International, 23(1), 6785.

Albrecht, S. and Travaglione, A. (2003), "Trust in public sector senior management", International Journal of Human Resource Management, Vol. 14 No. 1, pp. 76-92.

Arviana, Lidia, Nerissa, 2013, Hubungan Kepuasan Kerja Dengan Keterlambatan Pada Anggota di Organisasi Non-Profit X, http://library.binus.ac.id, akses 09 Nopember 2013.

Chen, Z. X., \& Francesco, A. M. (2000). Employee demography, organizational commitment, and turnover intentions in China: do cultural differences matter? Human relations, 53(6), 869-887.

Cheng, Y., \& Stockdale, M. S. (2003). The validity of the three-component model of organizational commitment in a Chinese context. Journal of Vocational Behavior, 62(3), 465-489.

Chen, Shuo, I, 2016, Work engagement and its antecedents and consequences: A case of lecturers teaching synchronous distance education courses. Oleh IShuo Chen (2016), Computers in Human Behavior xxx ,2016, 1-9

Chughtai, A.A. and Buckley, F. (2008), "Work engagement and its relationship with state and trait trust: a conceptual analysis", Journal of Behavioral and
Applied Management, Vol. 10 No. 1, pp. 47-71.

Handoko, Hani, (2014), Membangun Employee Engagement (Keterikatan Karyawan) www.mediakalla.co.id

Henle, C. A., Reeve, C. L., \& Pitts, V. E. (2010). Stealing time at work: Attitudes, social pressure, and perceived control as predictors of time theft. Journal of Business Ethics, 94(1), 53-67.

Hanisch, K. A., \& Hulin, C. L. (1991). General attitudes and organizational withdrawal: An evaluation of a causal model. Journal of Vocational Behavior, 39(1), 110-128.

Klein, H. J., Molloy, J. C., \& Cooper, J. T. (2009). Conceptual foundations: Construct definitions and theoretical representations of workplace commitments. Commitment in organizations: Accumulated wisdom and new directions, 1, 3-36.

Koslowsky, M., A. Sagie, M. Krausz and A. D. Singer, (1997), Correlates of Employee Lateness: Some Theoretical Considerations, Journal of Applied Psychology 82, 79-88

Luthans,F. (2006). Perilaku Organisasi. Edisi ke 10. Yogyakarta: Penerbit Andi

Macey, W.H. and Schneider, B. (2008), "The meaning of employee engagement", Industrial and Organisational Psychology, Vol. 1 No. 1, pp. 3-30.

Meyer, J. P., Allen, N. J., \& Smith, C. A. (1993). Commitment to organizations and occupations: Extension and test of a three-component conceptualization. Journal of applied psychology, 78(4), 538.

Mirsepasi Naser, Gholamreza Memarzadeh, Hosein Alipour , Mohammad Feizi, (2012), Citizenship and Withdrawal Behaviors in Contingency Cultures Student), Journal of Basic and Applied Scientific Research

Mone, E. M., \& London, M. (2018). Employee engagement through effective performance management: A practical guide for managers. Routledge 
Newman, A., Thanacoody, R., \& Hui, W. (2011). The impact of employee perceptions of training on organizational commitment and turnover intentions: a study of multinationals in the Chinese service sector. The International Journal of Human Resource Management, 22(8), 1765-1787.;

Rich, B.L., Lepine, J.A. and Crawford, E.R. (2010), "Job engagement: antecedents and effects on job performance", Academy of Management Journal, Vol. 53 No. 3, pp. 617-635.

Sadana, S., \& Vany, E. A. (2014). Pengaruh Employee Engagement dan Workplace Well-being terhadap Turnover Intention (Studi pada Kantor Akuntan Publik ABC \& Rekan).

Saks, M, Alan, (2006), Antecedents and consequences of employee engagement, Journal of Managerial Psychology, Vol. 21 Iss 7 pp. $600-619$

Saragih, S., \& Margaretha, M. (2013, June). Anteseden dan Konsekuensi Employee Engagement: Studi pada Industri Perbankan. In Seminar Nasional dan Call for Paper (pp. 1-21).

Steers, R. M. (1977). Antecedents and outcomes of organizational commitment. Administrative science quarterly, 46-56.

Sunarto, E. (2016). Pengaruh Employee Engagement Terhadap Komitmen Organisasional Serta Dampaknya Terhadap Kesiapan Berubah Pada Karyawan PT. Hati Energi Di Yogyakarta (Doctoral dissertation, UPN" Veteran" Yogyakarta).

Wagner, C. M. (2007). Organizational commitment as a predictor variable in nursing turnover research: literature review. Journal of advanced nursing, 60(3), 235-247.

www. Portalhr.com, memaknai engagement, akses tanggal 09 Nopember 2016.

Yulianti, P. (2016). Procedural Justice, Organizational Trust, Organizational Identification dan Pengaruhnya pada
Employee Engagement. Jurnal Manajemen Teori dan Terapan| Journal of Theory and Applied Management, 9(3). 